change in a chronic ulcer is certainly no commoner than is primary cancer of the duodenum. We all know that rare instances of the latter disease lave been reported but they are so rare that pathologists usually say that they do not accur at all. The fact about the supposed malignant degeneration of gastric ulcers is that cancer of the stomach occasionally arises in the form of a malignant ulcer. These cases are malignant from the outset, although in olderly patients their progress may be slow. When a case with a short history is encountered in a middle-aged or elderly person, who produces an $x$-ray picture showing a large ulcer, usually not very deep, on the lesser curvature of the stomach, the possibility should always be considered of this being malignant, and if there is any doubt operation becomes desirable.

The subject of complications is in itself a huge one, and any proper discussion of it is bound to bring us to the problem of what may be called "the unsuccessful gastroerterostomy." It is not my intention to enter into these cases at any length, but it is only right to realize, when one is discussing the alternative lines of treatment in cases of peptic ulcer, that there is no group of patients so calculated to fill both the physician and the surgeon with despair as that group in which a gastro-enterostomy has been performed and the operation has not been a success. Their symptoms are often far more trying than those of any ordinary case. I have seen such ratients die of harmorrhage five, eight, fourteen, and even seventeen rears after their operation. I have had cases which responcled to medical treatment in a dramatic manner; I have had others in which constant relapses occurred; and in all of them I have come to realize that further operation is more diffieult and uncertain than in any case where surgery has not previously been undertaken. I read articles by surgeons who write of reconstituting the original state of affairs, but in $m y$ experience this is an exceedingly difficult proceeding. I have seen cases where excision of large portions of the stomach and jejunum was successfully accomplished, and in others the shock of this operation has proved too much. There is little doubt that the position of these cases is a very serious one, and what is even more serious is that this operation is being light-heartedly performed by inexperienced surgeons in all parts of the country to-day. The problem, however, is primarily one for discussion anong surgeons, and cannot be dealt with here at greater length.

. Jomm. Infect. Dis., 1915, xvii, 219.

Christophe, L. :Arch. Mai. Appar. Digest., 1922, xii, 223

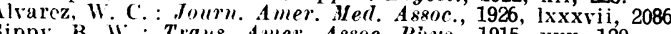

Nil, June 4th, 1927, p. 999. and Sirti. Journ., 1926, clxlv, 983 .

Crohn, B. R., and Einhorn, M. : Amer, Jourm. Merl. Sci., 1927, clxxiii, 691. Montier, F., and Porcher, P.: Presse Médicale, September 7th, 1927, Maclean, H., Jones, I., and Fildes, G. : Lancet, 1928, i, 14.

\section{THE TREATMENT OF ASTHMA,}

\section{And an Improvement of the Peptoned Agar Seruy.} BY

\section{A. GUNN AULD, M.D.,} LONDON.

Astrma is a constitutional condition, being one of a family of allergic disorders, and may be regarded as inherited. The family are all characterized by a state of sensitization. Whatever form the sensitization takes in a parent or grandparent, asthma may result in one or more of the offspring. A child which develops an allergic state on first contact with a foreign protein has been sensitized in the mother's uterus. Many cases of asthma are difficult to trace, and are put down as "acquired," but a remark of Salter may be opportune here.

"It is a curious fact," he says, " that several brothers and sisters in a family may be asthmatic without the parents being so. This would seem to suggest, in respect of disease, a principle with which the breeders of cattle are familiar: that certain com binations produce certain resulte, and lead to the crcation of certain peculiarities ... just as we sometimes see a family of red-haired children, both the parents of which have black hair."
It will be seen, therefore, how difficult it is to prove that asthma may be acquired. It may be dormant for many years. As Peshkin" correctly says, " the various etiologic protein sensitizations are merely the exciting factors, and not the basic cause of asthma." He also says that protein sensitization does not entirely explain the various manifestations connected with allergy. For instance, " 10 per cent. of the children with asthma who were skin-sensitive to various proteins showed no etiological connexion between protein sensitization and asthma."

When it is said that asthma may be due to toxic conditions simply, does not the question arise of how many toxic conditions are found without asthma, and how many cases of asthma there are without any toxic condition? In toxaemia there is usually hyperpiesis, but the opposite is found in asthma. Again, asthma is said to be nerrous in origin, that the parasympathetic overacts. Why should it do so? We have the fact brought out by Auer and Lewis" that anaphylaxis in animals occurs after section of the vagi, and destruction of the cord and medulla. T. Lewis, in his recent work, says that substances such as egg and fish, in susceptible persons, cause asthma, urticaria, etc. "That these manifestations are brought about also through a mechanism similar to that involved in animal anaphylaxis is open to little doubt, though the manner in which susceptibility is acquired remains unknown." Let us note that in both there is cosinophilia, and that relief is obtained through atropine.

In many asthmatics there are produced in the body substances, pathological but possibly also normal, which produce the attacks. Outside the body, matter or influences of all kinds, antigenic and non-antigenic, are swallowed or inhaled, etc., and act in the same way. The non-antigenic substances arouse asthma by changing the character or metabolism of certain of the proteins. Modifications of all sorts are found. Asthma is sometimes divided up into "kinds"-perhaps ten or more different kinds may be given. There is, however, but one kind, as the constitutions of all persons differ, and thus the various exciting substances differ, and they vary from time to time. One or two instances of the latter I mar give.

A lady, aged 43, consulted me in 1925 . She said she had very bad asthma from horses and cats, but from no other source. Her skin had never been tested, and in doing so it reacted strongly to horse dander and cat hair, but to nothing else. Her statement was therefore correct, so far. Then she went to France for a month or two, and remained well for a little time. She then wrote me that she had contracted bronchits and a violent attack

This astonished her very much. 12 , was brought to me from India, In another case, a boy, aged 12, was brought to me from India,
and his mother said he never had asthma in the warm weather in and his mother said he never had asthma in the warm weather in India, but on coming to this climate it came on, and it was
solely produced by cold. In the warm days of last August violent astlima came on. It was the first time in warm weather.

Many other instances might be given.

\section{Histaminc.}

Lately a good deal of fresh work has been done on histamine. Last March, Best, Dale, Dudley, and Thorpe ${ }^{5}$ stated that they had recovered histamine from liver and lung, which seemed to justify the expectation that this potent base was widely distributed in the tissues. It was found that $1.58 \mathrm{mg}$. of pure histamine had been isolated per kilogram of liver and $27.64 \mathrm{mg}$. per kilogram of lung. For the lungs this is a very high content. It may be released at the moment of death, but they doubt this. "It is conceivable," they write, "that the lung acts as an organ of internal secretion with respect to histamine, or that it merely captures histamine which has escaped into the venous blood." T. Lewis ${ }^{6}$ considers that histamine (or H-substance) is released from the cells of the skin in local injury, and from the tissue cells in general anaphylaxis. "A fundamental fact in the anaphylactic reaction is the liberation of H-substance."

Now histamine in a certain quantity may be released from the cells in anaphrlaxis, but that it is held inactive in the normal state is obrious, for, as Dale sars, "if suddenly released into the circulation of an animal, it would have a profound shock-like action." On May 27th 1922, in this Journal I recalled that it had been found by Hanke and Koessler that peptone which was perfectly 
histamine-free produced the typical peptone shock. Histamine shock is shorn of the following characteristics of peptone shock: extensive katabolism of body tissues, incoagulability of the blood, swelling of liver in dogs, pyrexia and desensitization. I also added the following remark, which is anticipatory: "In the katabolism of tissue connected with anaphylactic or anaphylactoid shock it is quite possible that histamine may be produced where celloxidation ceases." It is evident that in anaphylactic shock histamine may be produced, but it is only one constituent of the process.

\section{Nasal Disease and Asthma.}

It will be found in consulting the works of nasal specialists that they usually agree in adrocating treatment of all abnormal nasal conditions in asthma. This is perhaps only natural. If we consult the works of phrsicians, much less nasal treatment is recommended. Brodie and Dixon ${ }^{7}$ discovered that the most important reflex is from the nasal mucous nembrane. They found that the brenchial muscles were innervated by two sets of fibres, both of which ran in the vagus-a constrictor and a dilator set. When the upper and posterior part of the nasal septum was exposed to electrical, mechanical, or chemical excitation, bronchial spasm resulted. Section of the ragus entirely abolished the results. Francis ${ }^{8}$ showed that on touching certain points on the septum there ensued a considerable reduction of blood pressure, and on touching other points the pressure was raised. The higher the septum was touched with the cautery, the greater was the reduction of pressire; he attributes this action to a stimulation of the sympathetic fibres, and inhibition of vasorenstrictor action. Salter mentions sneezing, nothing more.

It is evident, however, that normally there is a strong reflex connexion between the nose and the lungs. I have known asthma greatly relieved by applying cocaine to the septum and turbinals. Peshkin ${ }^{9}$ states that in chronic nasal discharge, mouth-breathing, etc., in children, their removal does not relieve the asthma, but may even initiate it. The same is true, he says, of the removal of tonsils and adenoids. I have known tonsils and adenoids, when removed, to be followed by good enough results, when the patients were under treatment. Benefit may also be got (with the patients under asthma treatment) by freeing the nasal passages from obstruction, such as that caused by the middle turbinal in contact with the septum, and clearing the ethmoidal or other sinus, if need be. With polypi encounter a more difficult problem. I have several times noticed that their removal was followed by asthma. To give an instance.

In 1925 a gentleman, aged 52, consulted me. His nose had given him great trouble for many years. Polypi were present in both nostrils. He told me that he had never had asthma, but his sister had. I thought he might have the polypi removed, and sert him to an eminent nasal man. He then told me how greatly relieved he was. But in about two months he wrote haw greatly he had asthma for the first time. It recurred often.

If the polypi are recent, sometimes removal is advisable.

\section{The Role of Vaccines.}

Vaccines, autogenous and stock, have been in general use for many years, as a rule non-specifically. I doubt if it is warrantable to use them except in cases which are either definitely associated with, or else dependent upon, micro-organisms. Organisms in any part of the body may excite asthma, which possibly may be relieved by a vaccine, but it is generally in connexion with bronchitis that we find them. Is it the organism here that excites the asthma? A remark by Poulton ${ }^{10}$ is noteworthy. He says "It is more probable that the inflammation irritates the nerve endings in the mucous membrane of the bronchi, so as to produce a reflex local contraction in the muscles," However originated, it is necessary to relieve the inflammation as much as possible, and for this reason vaccines are given, but they do not markedly reduce the inflammation. They may be prophylactic, however. It may be mentioned that some asthmatic patients are very sensitive to vaccines, and it has been shown by Warren Crowe ${ }^{11}$ that peptone (Armour's No. 2) is the best desensitizer. He writes:

"Peptone is the method which offers the best chance of success. ... It is most gratifying to ... find patients who for weeks perhaps have been only able to take minute doses, perhaps 50,000 or 100,000 germs, whose symptoms constantly trouble them, who are unwell and ailing all the time with headache and loss of appetite, suddenly and dramatically, after a few doses of peptone, improve out of all knowledge. No one who has not seen th would believe that the effect of peptone treatment would be so striking."

Local irfection of any part of the body should be cleared if possible.

Koessler, Lewis, and Walker ${ }^{12}$ found that a mixture of micro-organisms from bronchial secretion, when grown in a blood broth, glycerol, amino-acid medium, forms substances which cause bronchial contraction in the living pithed guinea-pig, and arterial constriction in vitro. Histam mine was rarely found, and the poisons are ehemically unknown. Eiman and Wilmer ${ }^{13}$ found that many patients develop a sensitization to their own respiratory secretions. When the filtrate from the secretion is used hypodermically relief is sometimes experienced, but serere asthmatic seizures also occur.

\section{Specific Treatment.}

Some time ago, after the work of Chandler Walker, what may be termed the specific treatment of asthma began to be practised with much zest by the Americans. A great many substances, mostly proteins, were tested on the skin. The same thing was done in this country by Coke. Descnsitization was attempted by the complete withdrawal of those substances which seemed from the skin tests to affect the patient, and also by the giving of minute quantitics of the food by the mouth, or the hypodermic injection of very small dilutions of the substance. About 50 per cent. of the cases tested were said to give positive results. Of these a large proportion occurred in children and young persons, so that the majority of adults were negative. It is difficult to see how the positive cases could usually be treated $\mathrm{ho}$ the mouth or by hypodermic injection, as they were nearly all multisensitive, some being positive to a great many substances. It is not necessary to go into any detail, but it may be said that the method has largely broken down. Nevertheless, a clear light has been thrown on the modus operandi of many of these substances, and some excellent results have been obtained, so that it is unjust to depreciate it. It is a distinct advance in our knowledge, and the time may come when definitely specific cases can be made to respond more to specific therapy, though at present a considerable number do not do so.

Improvement of Peptoned Agar Serum.

As asthma is a sensitization, any substance which desensitizes may be termed "specific," just as there are specifics for the exciting substances. Peptone is the best desensitizer we know of at present, though its action is much greater in some cases than in others. It desensitizes the body generally, apart from antigens. It is stated by McIntosh'14 that, if one does not use a specific antigen, the results "depend chiefly on the general tissue reartion and the leucocyte response." Peptone produces both these factors, and also an unknown change. In certain cases which are irresponsive to any form of treatment (as known) it excites speedy improvement, yet there are other cases which respond but little. Armour's No. 2 peptone is best, a.s it contains no histamine, and has primary and secondary proteoses. Adam, ${ }^{15}$ in the last edition of his work on asthma, says: "I prefer... peptone treatment to any other mode of desensitization." In some cases the peptone is assisted by an iodine mixture.

As the incubation of the patient's blood with peptone, which I recommended in 1924, failed after a time owing to some change in the peptone,* it was recommended last March $^{16}$ to make the serum of the patient anaphylartic with agar, then add powdered peptone, and then phenol. It is unnecessary here to go into the reasons for this, as they will be found in the works of Karsner and Ecker, and Dale and Kellaway, mentioned in the paper. I have found that the slight precipitation which occurs after

* The peptone may be better now. I have not tested it since 
adding phenol is a drawback, and now recommend the following method: Incubate the agar serum for about two hours at $37^{\circ} \mathrm{C}$. Then a 30 per cent. solution of peptone is taken, and 4 c.cm. of it is mixed with $2 \frac{1}{2}$ minims of phenol (measured) for each ounce of the peptoned agar serum. No precipitate will be found in this peptone solution.* It is then poured into the agar serum, and mixed up with it, when the colloidal solution remains perfectly clear. It is unnecessary to incubate further. It is best to use the patient's own serum, as it contains some appropriate antibody, more or less.

When a case has been thoroughly examined, the diet, etc., arranged, and any endocrine defect attended to; first try intravenous injection of peptone ( 5 per cent.) up to $2 \frac{1}{2}$ or $3 \mathrm{c.cm}$.; if after a time, say four to five weeks, but little improvement is found, carefully and slowly introduce into the vein peptoned agar serum $\left(\frac{1}{2}\right.$ c.cm. up to $3 \frac{1}{2}$ or 4 c.cm.) when, in many cases, excellent results will be obtained.

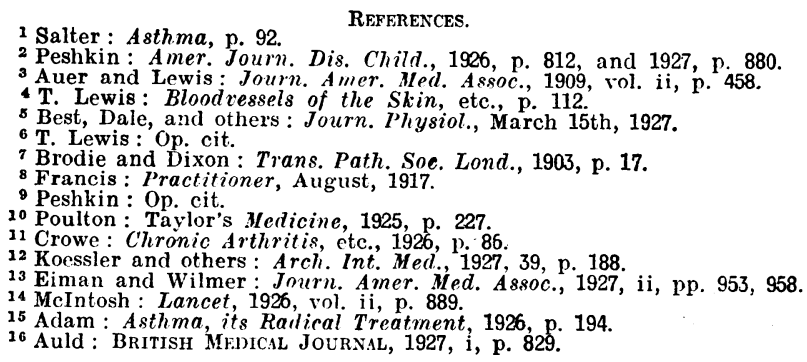

\section{THE FIXATION OF ANTISEPTICS BY DRESSINGS} AND TISSUES :

Its Importance in Wound Treatment, with Special Reference to Acriflavine. BY

J. G. GRAHAM, M.B., Сн.B.,

EXTRA DISPENSARY PHYSICIAN, FORMERLY CASUALTY OFFICER, WESTERN INFIRMARY, GLASGOW.

The application of an antiseptic to infected tissues by means of wet dressings ought to be regulated by a knowledge of several factors. These comprise principally, of course, the relative toxic effects of the drug on the tissues and on the pathogenic organisms, and the influence exerted on antiseptic action by the presence of exudate. But it is also of importance to know the extent to which dressings and the tissues may fix the chemical substances employed, since upon this will largely depend the amount of antiseptic remaining free to act upon the organisms disposed at or near the surface of the wound. The latter point is dealt with in the present communication, and it is shown that with a certain class of antiseptics, to which acriflavine belongs, the capacity of the cotton dressings to absorb the drug must be taken into account in determining the strength of solution which is to be employed.

Experiments to measure the absorptive capacity of gauze for acriflavine, phenol, and mercuric chloride were carried out by soaking swabs of absorbent gauze of arerage size ( 5 grams) in measured amounts of solution of determined strengths. The swabs had been previously well washed in distilled water and dried. After soaking for various periods the swabs were removed from the solutions and as much fluid as possible was allowed to drain away in the course of a minute. Then an estimation was made of the concentration of the substance in the fluid expressed by firmly wringing out the swab, and also the concentration remaining in the fluid residue in which the gauze had been soaked. When fixation of the antiseptic by the gauze had occurred the amount which was subsequently given off when the swab was soaked in distilled water was also determined. In the first instance the behaviour of gauze when treated with investigated. Quantitative titrations were carried out in each

* The 30 per cent. peptone solution may be made by heating peptone in saline at about $90^{\circ}$ C. for a considerable time, shaking up, adding 0.5 per cent. phenol, allowing to stand for a few days and filering. If necessary
it can be obtained clear and sterile from Martindale (10, New Cavendish
Street, W.1) in any amount, however small instance according to standard methods; silver nitrate being used for sodium chloride, potassium iodide for mercuric chloride, and bromine water for phenol. The same procedure was followed in each case, and the sodium chloride experiment will alone be dealt
with in detail. A 5-gram swab, previously autoclaved and sterilized at $25 \mathrm{lb}$. pressure for two hours, was placed in a beaker containing 100 c.cm. 0.85 per cent. $\mathrm{NaCl}$ solution, and allowed to soak for one hour. It was then removed and allowed to drip into a beaker for one minute before being wrung out into a second beaker. (It should be noted that from a 5 -gram swab dripping
wet some $35 \mathrm{c.cm}$. of fluid can be expressed, while approximately wet some $35 \mathrm{c.cm}$. of fluid can be expressed, while approximately
$6 \mathrm{c.cm}$. of water are firmly held.) The swab was found to have no affinity for the sodium chloride. Similar results were obtained when a swab was soaked in mercuric chloride 1 in 1,000 for one hour, or in 4 per cent. phenol for forty-eight hours.

The aissorption of acriflavine was estimated by comparing in uniform test-tubes the tint of $5 \mathrm{c.cm}$. of the expressed fluid, or the residue, with a series of standards consisting of $5 \mathrm{c.cm}$. of the following strengths, 1 in $1,000,1$ in $2,000,1$ in 3,000 down to 1 in $10,000,1$ in $20,000,1$ in 30,000 , down to 1 in 100,000 , in overcome by adding 0.3 c.cm. strong hydrochloric acid to each
tube. In this way a brownish-yellow colour was obtained which tube. In this way a brownish-yellow colour was obtained which colour of the solutions remained constant for about a fortnight. colour of the solutions remained constant for about a fortnight.
The results were in sharp contrast to those with the previously The results were in sharp contrast to those with the previously
mentioned substances. Thus on soaking a 5-gram swab in mentioned substances. Thus on soaking a 5-gram swab in
100 c.cm. 1 in 1,000 acriflavine solution-that is about three times as much fluid as the gauze will hold without dripping-there was a rapid absorption for the first three minutes, when the concena rapion of the dye for the first three minutes, when the concentration of the dye in the residue was reduced to 1 in 1,200 , and
to 1 in 1,600 in the fluid expressed from the swab. The gauze to 1 in 1,600 in the fluid expressed from the swab. The gauze
thereafter continued to absorb at a much reduced rate until the saturation point was reached in about twenty-four hours, when the residue and the fluid expressed from the swab were both reduced to a concentration of 1 in 1,800.

In view of the active absorptive power of the gauze for acriflavine it appeared that if a number of swabs were successively soaked in a limited quantity of the solution, the antiseptic property of the latter would rapidly become reduced to a low practice when wounds were being treated with the antiseptic it was decided to carry out quantitative experiments. Nine 5-gram swabs were soaked successively in $500 \mathrm{c.cm}$. acriflavine 1 in 1,000 for periods of three minutes; each swab on removal was allowed to drip into the fluid for one minute. After the removal of the sixth swab the concentration of the residual fluid had fallen to 1 in 1,300, and after the ninth to 1 in 4,000. The first, third, and ninth swabs were placed in Petri dishes for twenty-four hours in a cool place in order to allow of maximal fixation of the antiseptic and to prevent evaporation. These Swabs were then wrung out
into separate beakers. (There was little difference in the conceninto separate beakers. (There was little difference in the concen-
tration of the dye obtained at the beginning and the end of wringing of each swab.) The fluid wrung from the first swab was of strength 1 in 1,400, from the sixth 1 in 2,000, and from the ninth 1 in 4,000 . Therefore the concentration of flavine in the
fluid wrung from the last swab is such as has a powerful antiseptic fluid wrung from the last swab is such as has a powerful antiseptic
action. When six swabs were simultaneously soaked for three minutes in $250 \mathrm{c.cm} .1$ in 1,000 acriflavine-nearly the minimum amount of fluid capable of efficiently soaking such a number of swabs-the residue was reduced in strength to 1 in 3,000 , and the fluid expressed from the swabs after ten minutes contained slightly less than 1 in 3,000 .

A marked impoverishment' in antiseptic property of the available fluid occurred when six swabs were simultaneously soaked for three minutes in $250 \mathrm{cccm}$. of 1 in 2,000 acriflavine. The
residue was reduced to a strength slightly in excess of 1 in 20,000 and the fluid wrung from the swabs to about 1 in 30,000

The experiments were then repeated with a 5-gram swab soaked in 100 c.cm. of a 1 in 5,000 solution of acriflavine, since this strength has been frequently recommended for use with gauze strength has been frequently recommended for use with gauze
swabs. After three minutes the concentration in the residue was swabs. After three minutes the concentration in the residue was
reduced to 1 in 9,000 , and that in the fluid wrung from the swab reduced to 1 in 9,000 , and that in the fluid wrung from the swab
to between 1 in 10,000 and 1 in 20,000 . The saturation point of to between 1 in 10,000 and 1 in 20,000 . The saturation point of
the gauze was approximately reached after soaking for twenty-four the gauze was approximately reached after soaking for twenty-four
hours; then both the residue and the fluid wring from the swab hours; then both the residue and the fluid wring from the swab
showed a coneentration slightly greater than 1 in 20,000 . When showed a concentration slightly greater than 1 in 20,000 . When
six 5-gram swabs were soaked successivcly in a solution of 500 c.cm. of acriflavine 1 in 5,000 for periods of three minutes $500 \mathrm{c.cm}$. of acriflavine 1 in 5 , ove for periods of three minutes 1 in 100,000, which is approximately the limit at which antiseptic action takes place. When six swabs were added simultancously to $500 \mathrm{ccm}$. of acriflavine 1 in 5,000 and allowed to soak for three minutes the residue was reduced to a concentration of 1 in 20,000, and the fluid wrung from the swabs to rather less than 1 in 30,000. Accordingly, when a number of swabs are soaked either successively or simultaneously in an amount of 1 in 5,000 solution of acriflavine, which is double that suffirient to saturate the swabs with fluid, the arai

A gauze swab saturated by soaking for about seventy-two hours in three successive portions of $100 \mathrm{c.cm}$. of acriflavine 1 in 1,000 , and afterwards wrung out and dried, holds the dye' with considerable firmness. But when a swab so treated was then soaked for twenty-four hours in $100 \mathrm{c} . \mathrm{cm}$. of 0.85 per cent. saline the concentration in the fluid was 1 in 6,000 . A similar experiment carried out with a swab saturated in acriflavine 1 in 5,000 parted to the fluid a concentration of the drug of 1 in 20,000 . In order to form some estimate of the capacity of the tissues minced ox muscle. The tissue was left in running water for minced ox muscle. The tissue was left in running water for
twenty-four hours to remove haemoglobin and other soluble 